\title{
Human Plasma Kallikrein Releases Neutrophil Elastase during Blood Coagulation
}

\author{
Yanina T. Wachtfogel, Umberto Kucich, Harold L. James, Cheryl F. Scott, \\ Marc Schapira, Morris Zimmerman, Allen B. Cohen, and \\ Robert W. Colman, Thrombosis Research Center and the Hematology- \\ Oncology and Pulmonary Sections, Department of Medicine, Temple \\ University School of Medicine, Philadelphia, Pennsylvania 19140; Graduate \\ Hospital Research Center, Division de Rhumatologie, Hospital Cantonal \\ Universitaire, 1211 Geneve, 4, Switzerland; Merck Sharp \& Dohme \\ Laboratories, Rahway, New Jersey 07065
}

A B S T R A C T Elastase is released from human neutrophils during the early events of blood coagulation. Human plasma kallikrein has been shown to stimulate neutrophil chemotaxis, aggregation, and oxygen consumption. Therefore, the ability of kallikrein to release neutrophil elastase was investigated. Neutrophils were isolated by dextran sedimentation, and elastase release was measured by both an enzyme-linked immunosorbent assay, and an enzymatic assay using $t$-butoxycarbonyl-Ala-Ala-Pro-Val-amino methyl coumarin as the substrate. Kallikrein, 0.1-1.0 U/ml, $(0.045-0.45$ $\mu \mathrm{M})$, was incubated with neutrophils that were preincubated with cytochalasin B $(5 \mu \mathrm{g} / \mathrm{ml})$. The release of elastase was found to be proportional to the kallikrein concentration. Kallikrein released a maximum of $34 \%$ of the total elastase content, as measured by solubilizing the neutrophils in the nonionic detergent Triton $\mathrm{X}-100$. A series of experiments was carried out to determine if kallikrein was a major enzyme involved in neutrophil elastase release during blood coagulation. When 10 million neutrophils were incubated in $1 \mathrm{ml}$ of normal plasma in the presence of $30 \mathrm{mM} \mathrm{CaCl}_{2}$ for $90 \mathrm{~min}, 2.75 \mu \mathrm{g}$ of elastase was released. In contrast, neutrophils incubated in prekallikrein-deficient or Factor XII-deficient plasma released less than half of the elastase, as compared with normal plasma. The addition of purified prekallikrein to prekallikrein-deficient plasma restored neutrophil elastase release to

This work was presented in part at the American Heart Association Meeting, Dallas, TX, 15-18 November 1982 and published in abstract form in 1982, Circulation, 66:292a.

Address all correspondence to Dr. Colman at Temple University School of Medicine.

Received for publication 5 May 1983 and in revised form 28 July 1983. normal levels. Moreover, release of elastase was enhanced in plasma deficient in CI-inhibitor, the major plasma inhibitor of kallikrein. This release was not dependent upon further steps in the coagulation pathway, or on C5a, since levels of elastase, released in Factor XI- or C5-deficient plasma, were similar to that in normal plasma, and an antibody to C5 failed to inhibit elastase release. These data suggest that kallikrein may be a major enzyme responsible for the release of elastase during blood coagulation.

\section{INTRODUCTION}

Granules from viable human neutrophils contain a variety of enzymes known to be released into the extracellular milieu. Enzyme release results from phagocytosis, as well as stimulation by a variety of soluble agents, such as $\mathrm{N}$-formyl-methionyl-leucyl-phenylalanine (FLMP), ${ }^{1}$ or the plasma chemotaxin, C5a (1). One of the more important neutrophil enzymes found in the azurophilic granules is elastase (EC 3.4.21.37), which may be responsible for proteolysis of vital structures in the lung (2). Plow (3) has shown that, in vitro, human neutrophils release elastase during blood coagulation, independently of thrombin. Purified human plasma kallikrein, which is a chemotoxin for neutrophils (4) as well as a stimulator of aerobic glycolysis in neutrophils (5), also aggregates human neutrophils, and stimulates oxygen consumption (6). This effect, which requires the active enzyme, occurs at kallikrein concentrations that may occur during blood coagula-

\footnotetext{
${ }^{1}$ Abbreviations used in this paper: DFP-HNE, diisopropylfluorophosphate-inactivated HNE; ELISA, enzyme-linked immunosorbent assay; FMLP, $N$-formyl-methionyl-leucylphenylalanine; HNE, human neutrophil elastase; SBTI, soybean trypsin inhibitor.
} 
tion. In this study, we have demonstrated that in a purified system kallikrein can release elastase from human neutrophils, and we have evaluated its contribution towards elastase release during blood coagulation.

\section{METHODS}

Soybean trypsin inhibitor (SBTI), FLMP, and cytochalasin B were obtained from Sigma Chemical Co., St. Louis, MO. $t$-Butoxycarbonyl-Ala-Ala-Pro-Val-amino methyl coumarin, was synthesized by Dr. Zimmerman (7) at Merck Sharpe \& Dohme Laboratories, Rahway, NJ. Flat-bottomed polystyrene microtiter plates (96 wells-immulon No. 2) were purchased from Dynatech Laboratories, Alexandria, VA. Goat anti-rabbit IgG (heavy and light chains), conjugated to horseradish peroxidase, was obtained from Cappel Laboratories, West Chester, PA. Human urinary kallikrein was a gift from Drs. Julie Chao and Harry Margolius, Charleston, SC (8). Anti-C5 (IgG fraction) was purchased from Atlantic Antibodies, Scarborough, ME.

Plasma. Factor XI-deficient plasma was donated to us by a patient with $<1 \%$ Factor XI. Plasma with $17 \%$ CI-inhibitor was donated to us by a patient with hereditary angioedema. Factor XII-deficient plasma was kindly supplied by Dr. Margaret Johnson, Wilmington, DE. Prekallikrein-deficient plasma was generously supplied by $\mathrm{Dr}$. Charles Abildgaard, Davis, CA. C5-deficient plasma, containing $<2 \%$ of both normal antigenic and hemolytic activity, was a generous gift of Dr. Philip Craddock, University of Kentucky Medical School. For individual experiments, venous blood was collected (after obtaining informed consent) into plastic syringes containing 1 vol trisodium citrate for each $9 \mathrm{vol}$ of blood (final citrate concentration, $13 \mathrm{mM}$ ). Plasma was centrifuged at $5,000 \mathrm{~g}$ for $15 \mathrm{~min}$ at $4^{\circ} \mathrm{C}$ to remove all cells.

Purified blood components. Kallikrein was prepared by activation of purified prekallikrein by Factor XII fragments (9). On nonreduced $10 \%$ sodium dodecyl sulfate gels, two bands of $M_{\mathrm{r}}=88,000$ and 85,000 were found. The preparation contained no measurable Factor XI, XIa, XII, XIIa, plasminogen, or plasmin. Two different kallikrein preparations were used, with similar results. The first preparation was free of IgG, and the second contained $5 \mathrm{mg}$ nonaggregated IgG/mg kallikrein. For certain experiments, kallikrein $(0.45 \mu \mathrm{M})$ was inactivated by preincubation with SBTI $(250$ $\mu \mathrm{M}$ ) for $5 \mathrm{~min}$ at $23^{\circ} \mathrm{C}$. The normal concentration of prekallikrein in plasma is one coagulant unit per milliliter, $(0.45$ $\mu \mathrm{M})$. Factor XII fragments were purified as previously described (9).

Human neutrophil elastase was purified to homogeneity, as described in reference 10 . Antibody raised in rabbits to human neutrophil elastase produced one precipitin arc, either by immunodiffusion or immunoelectrophoresis against either purified elastase or a crude neutrophil extract.

Neutrophil isolation. Human neutrophils were isolated from blood and anticoagulated with acid-citrate-dextrose by sedimentation in $1 \%$ dextran $\left(M_{\mathrm{r}}=100,000-200,000\right)$, followed by a brief hypotonic or $\mathrm{NH}_{4} \mathrm{Cl}$ lysis of residual erythrocytes $(11,12)$. From one unit of whole blood, we isolated $\sim 8 \times 10^{8}$ neutrophils to $\sim 80 \%$ purity.

Neutrophil release in a purified system. 10 million isolated neutrophils were incubated in $1 \mathrm{ml}$ of Hanks' balanced salt solution containing $2 \mathrm{mM} \mathrm{CaCl}_{2}$, at $37^{\circ} \mathrm{C}$, while stirring at $1,200 \mathrm{rpm}$ in the presence of $5 \mu \mathrm{g} / \mathrm{ml}$ cytochalasin $\mathrm{B}(13)$. After $20 \mathrm{~min}$, various agonists were added to this incubation mixture. Upon centrifugation at $13,000 \mathrm{~g}$ for $5 \mathrm{~min}$ at $23^{\circ} \mathrm{C}$ in a Micro-Centrifuge (model 235A Fisher Scientific Co., Pittsburgh, PA), the supernatants were recovered and frozen at $-20^{\circ} \mathrm{C}$ until enzymes were measured.

Neutrophil release in a plasma system. Neutrophils (1 $\times 10^{7} / \mathrm{ml}$ ) not primed with cytochalasin $B$ were resuspended in normal or factor-deficient plasma, without stirring, at $23^{\circ} \mathrm{C}$, in polypropylene tubes. Then $\mathrm{CaCl}_{2}$ (final concentration 30 $\mathrm{mM}$ ) was added, and $1-\mathrm{ml}$ samples were aliquoted. At various times, SBTI (250 $\mu \mathrm{M}$ final concentration) was added, and each sample was centrifuged at $13,000 \mathrm{~g}$ for $5 \mathrm{~min}$ at $23^{\circ} \mathrm{C}$.

Fluorimetric measurement of neutrophil elastase. Neutrophil elastase activity, released in a purified system as described above, was measured, using the fluorescent substrate, $t$-butoxycarbonyl-Ala-Ala-Pro-Val-amino methyl coumarin (7). The percent of elastase activity released was calculated, relative to the total elastase activity, as determined by solubilizing intact neutrophils in $0.5 \%$ Triton X-100 (14).

Enzyme-linked immunosorbent assay (ELISA) for neutrophil elastase. An indirect, competitive ELISA was performed, as described in reference 15, with the following modifications. Flat-bottomed (immulon No. 2), 96-well polystyrene microtiter plates were used instead of polystyrene tubes $(12 \times 75 \mathrm{~mm})$. Antibody and human neutrophil elastase (HNE) were preincubated at $16^{\circ} \mathrm{C}$ overnight in glass tubes before their addition to the microtiter plate, previously coated with $20 \mathrm{ng}$ of antigen per well. The time of competition between insoluble antigen noncovalently linked to the microtiter plate and soluble antigen in the fluid phase for the limiting amount of primary antibody sites was reduced from 3 to $1 \mathrm{~h}$ at $16^{\circ} \mathrm{C}$. Goat anti-rabbit IgG, conjugated with horseradish peroxidase, was then added, the plate washed, the substrate added, and the absorbance was measured at $450 \mathrm{~nm}$. Fig. 1 shows that the addition of increasing amounts of diisopropylfluorophosphate-inactivated HNE (DFP-HNE) decreased the amount of color development, as compared with control, and was directly proportional to the amount of DFP-HNE added.

Lactate dehydrogenase assay. Release of the cytoplasmic enzyme, lactate dehydrogenase, was analyzed by the method of Reeves and Fimognari (16), to determine if neutrophil lysis had occurred.

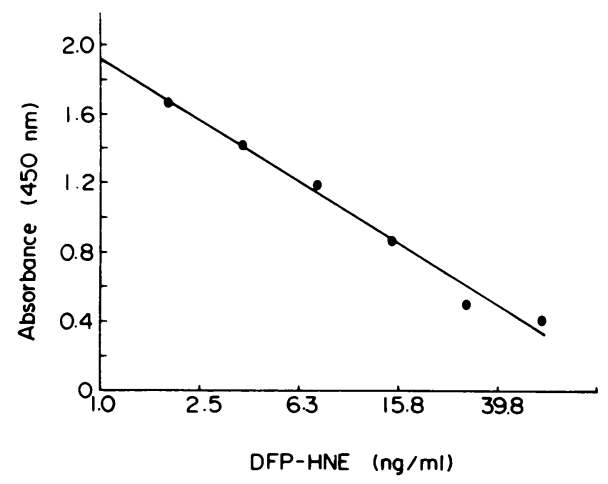

Figure 1 Competitive ELISA for HNE. The ELISA was performed as described in Methods. A standard curve was constructed using various concentrations of DFP-HNE and the resultant absorbance plotted on the ordinate. All values are a mean of at least three determinations. 


\section{RESULTS}

Release of elastase from washed human neutrophils by plasma kallikrein. Purified human plasma kallikrein, 0.1-1.0 U/ml $(0.045-0.45 \mu \mathrm{M})$, induced neutrophils primed with cytochalasin B to release $12-34 \%$ of their total elastase content. Kallikrein, $(0.05 \mathrm{U} / \mathrm{ml}$, $0.023 \mu \mathrm{M}$ ) released only $2 \%$ elastase, which did not differ significantly from the buffer control. In the absence of cytochalasin B, only $1-3 \%$ release was found. The release of the enzyme was determined by a functional assay for elastase, using the fluorescent substrate (Fig. 2). This release was not due to cell lysis, since $<2 \%$ of the lactate dehydrogenase that can be solubilized by $0.5 \%$ Triton X-100 appeared in the supernatant. Neutrophils incubated with human plasma prekallikrein $(0.45 \mu \mathrm{M}, 1 \mathrm{U} / \mathrm{ml})$, human plasma Factor XII fragments $(1.0 \mu \mathrm{g} / \mathrm{ml})$, human urinary kallikrein $(0.45 \mu \mathrm{M})$, SBTI-inactivated kallikrein $(0.45 \mu \mathrm{M})$, or calcium alone, failed to release significant levels of HNE and showed an absolute requirement for calcium (Table I). To assess the kinetics of the elastase released, purified human plasma kallikrein, $1.0 \mathrm{U} / \mathrm{ml}(0.45 \mu \mathrm{M})$, was incubated with neutrophils that were primed with cytochalasin B in Hanks' balanced salt solution, which contained no plasma. Aliquots were removed at various times, and the kallikrein was inactivated with SBTI $(250 \mu \mathrm{M})$. At this concentration, 550 -fold excess of inhibitor over enzyme, complete inactivation of kallikrein by SBTI was achieved in $5 \mathrm{~s}$. Within $15 \mathrm{~s}$. of addition of kallikrein to neutrophils, $1.31 \pm 0.06 \mu \mathrm{g}$

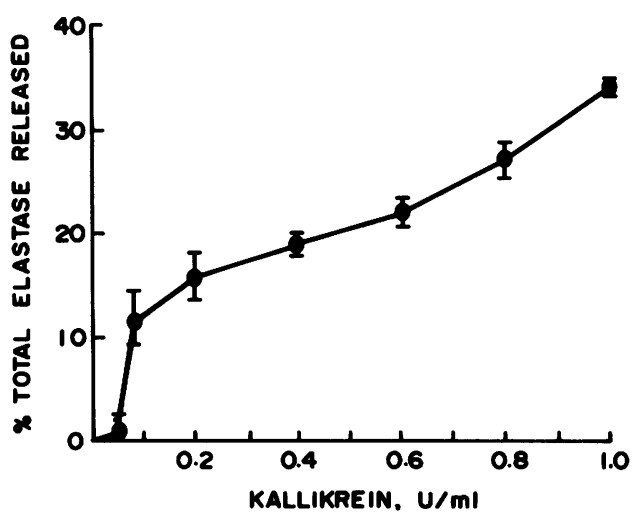

Figure 2 Kallikrein concentration-dependent release of HNE from neutrophils. Neutrophils $\left(1 \times 10^{7} / \mathrm{ml}\right)$ were incubated with cytochalasin $B(5 \mu \mathrm{g} / \mathrm{ml})$ and varying concentrations of human plasma kallikrein in Hanks' balanced salt solution, containing $2 \mathrm{mM} \mathrm{CaCl}$ with stirring at $37^{\circ} \mathrm{C}$ for $20 \mathrm{~min}$. Samples were centrifuged at $13,000 \mathrm{~g}$ for $5 \mathrm{~min}$, and the percent of total $\mathrm{HNE}$ activity was measured in these supernatants, employing the fluorescent substrate $t$-butoxycarbonyl-Ala-Ala-Pro-Val-amino methyl coumarin. The data represents mean $\pm S E M$ of three determinations.
TABLE I

Effect of Agonists on Neutrophils

\begin{tabular}{lcc}
\hline \multicolumn{1}{c}{ Agonist } & $\begin{array}{c}\text { No. of } \\
\text { experiments }\end{array}$ & $\begin{array}{c}\text { Micrograms } \\
\text { HNE released } \\
\text { per milliliter }\end{array}$ \\
\hline $\begin{array}{l}\text { Human plasma kallikrein }(0.45 \mu \mathrm{M}) \\
\text { Human plasma prekallikrein }\end{array}$ & 6 & $2.46 \pm 0.10$ \\
$\quad(0.45 \mu \mathrm{M})$ & 3 & $0.14 \pm 0.01$ \\
$\begin{array}{l}\text { Human plasma Factor XII fragments } \\
\quad(1.0 \mu \mathrm{g} / \mathrm{ml})\end{array}$ & 3 & $0.23 \pm 0.13$ \\
$\begin{array}{l}\text { Human urinary kallkrein }(0.45 \mu \mathrm{M}) \\
\text { FMLP }(0.2 \mu \mathrm{M})\end{array}$ & 2 & $0.12 \pm 0.00$ \\
$\begin{array}{l}\text { Human plasma kallikrein }(0.45 \mu \mathrm{M}) \\
\quad \text { and SBTI }(250 \mu \mathrm{M})\end{array}$ & 3 & $2.20 \pm 0.31$ \\
No calcium added & 3 & $0.09 \pm 0.05$ \\
\hline
\end{tabular}

Neutrophils $\left(1 \times 10^{7} / \mathrm{ml}\right)$ in Hanks' balanced salt solution were preincubated with cytochalasin $\mathrm{B}(5 \mu \mathrm{g} / \mathrm{ml})$ and $\mathrm{CaCl}_{2}(2 \mathrm{mM})$ for $20 \mathrm{~min}$ at $37^{\circ} \mathrm{C}$. The agonists listed above were then added and incubated for an additional $20 \mathrm{~min}$. After centrifugation (see Methods), the supernatants were assayed for HNE using a competitive ELISA. Results are mean \pm SEM

HNE was present in the supernatant, and at the end of $60 \mathrm{~min}$, this release increased to $2.43 \pm 0.06 \mu \mathrm{g} \mathrm{HNE}$ (Fig. 3).

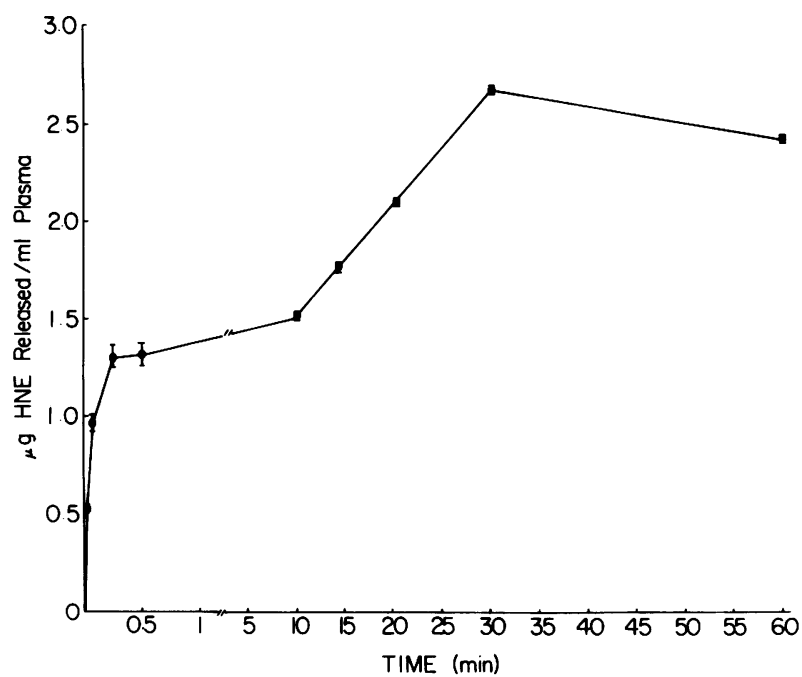

Figure 3 Time-dependent release of HNE from neutrophils stimulated with kallikrein. Neutrophils $\left(1 \times 10^{7} / \mathrm{ml}\right)$ were preincubated with cytochalasin $\mathrm{B}(5 \mu \mathrm{g} / \mathrm{ml})$ in Hanks' balanced salt solution containing $2 \mathrm{mM} \mathrm{CaCl}$ with stirring at $37^{\circ} \mathrm{C}$. Purified human plasma kallikrein, $1 \mathrm{U} / \mathrm{ml}(0.45 \mu \mathrm{M})$, was then added. At selected time intervals, SBTI $(250 \mu \mathrm{M})$ was added to inactivate the kallikrein. Samples were then centrifuged at $13,000 \mathrm{~g}$ for $5 \mathrm{~min}$, and $\mathrm{HNE}$ levels were measured in these supernatants by an indirect competitive ELISA. The data represent mean \pm SEM of three determinations. 
Release of elastase in normal plasma. When $10^{7}$ neutrophils were resuspended in $1 \mathrm{ml}$ of normal human plasma, in the presence of $30 \mathrm{mM} \mathrm{CaCl}_{2}$, at $23^{\circ} \mathrm{C}$, in polypropylene tubes, a slow release of elastase resulted with a maximum of $2.75 \mu \mathrm{g} / \mathrm{ml}$ at $90 \mathrm{~min}$ (Fig. 4). Since kallikrein formation in plasma is influenced by the surface composition of the tube used, we measured elastase release in polystyrene and glass tubes under similar conditions. At $2 \mathrm{~min}$, the percentage maximum release of elastase in polypropylene, polystyrene, and glass tubes, was 28,28 , and $100 \%$, respectively. At 5 min, the corresponding values were 31,92 , and $100 \%$, respectively. Thus, the release of elastase appeared to be very sensitive to the nature of the vessel surface, with release most rapid in glass, followed by polystyrene, and polypropylene.

Release of elastase in human deficient plasma. Since kallikrein could release elastase in a purified system, and since the nature of the surface profoundly influenced the role of elastase release, we studied neutrophil activation in plasma from individuals deficient in the contact system enyzmes. When Factor XI-deficient plasma was used (Fig. 4), the level of elastase released was similar to that in normal plasma. To assess the contribution of kallikrein during this process, $10^{7}$ neutrophils were resuspended in $1 \mathrm{ml}$ of either prekallikrein-deficient or Factor XII-deficient plasma. When $\mathrm{CaCl}_{2}$ was added $(30 \mathrm{mM})$ to the cells resuspended in either prekallikrein-deficient or Factor XII-deficient plasma, less than half of the concentration of elastase was released, as compared with normal plasma (Fig. 4).

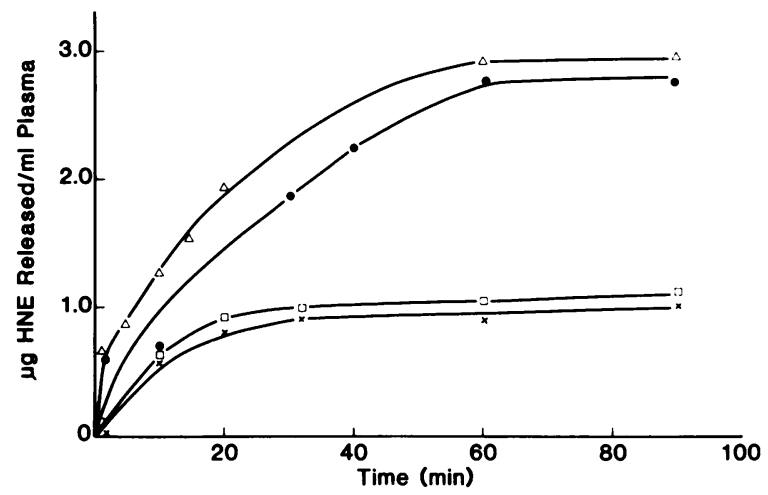

Figure 4 Kinetics of release of HNE from human neutrophils by plasma kallikrein. Isolated human neutrophils $\left(1 \times 10^{7}\right)$ were resuspended in $1 \mathrm{ml}$ of $(\bullet)$ normal $(\Delta)$ Factor XIdeficient, $(\square)$ Factor XII-deficient, or $(X)$ prekallikrein-deficient human plasma containing $30 \mathrm{mM} \mathrm{CaCl} 2$ in 12 $\times 75-\mathrm{mm}$ polypropylene tubes at $23^{\circ} \mathrm{C}$. At various times, aliquots were centrifuged at $13,000 \mathrm{~g}$ for $5 \mathrm{~min}$ and $\mathrm{HNE}$ was determined in the supernatants by a competitive ELISA. The data are a representative experiment of three such performed.

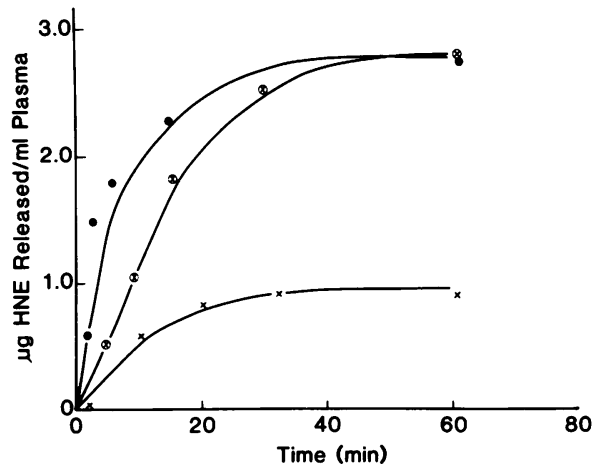

Figure 5 Effect of reconstitution of prekallikrein-deficient plasma on HNE release from human neutrophils. Isolated neutrophils $\left(1 \times 10^{7}\right)$ were resuspended in $(0)$ normal, $(X)$ prekallikrein-deficient, or $(\otimes)$ prekallikrein-deficient plasma reconstituted with $1.0 \mathrm{U} / \mathrm{ml}$ purified human plasma prekallikrein. Each plasma was recalcified to a final concentration of $30 \mathrm{mM} \mathrm{CaCl}_{2}$, and the neutrophil suspension was incubated in $12 \times 75-\mathrm{mm}$ polypropylene tubes at $23^{\circ} \mathrm{C}$. At selected times, aliquots were centrifuged at $13,000 \mathrm{~g}$ for $5 \mathrm{~min}$, and HNE levels were determined in these supernatants by a competitive ELISA. This experiment represents one of two studies.

Upon reconstitution of the prekallikrein-deficient plasma with purified prekallikrein, $1.0 \mathrm{U} / \mathrm{ml}(0.45$ $\mu \mathrm{M})$, the level of neutrophil elastase released approached the level that was observed in normal plasma (Fig. 5). The measureable formation of plasma kallikrein exposed to a surface is twice as great in plasma depleted of Cī-inhibitor, the major inhibitor of kallikrein (9). Therefore, we compared the maximum extent of elastase release from the same neutrophils resuspended in normal and $\mathrm{CI}$-inhibitor deficient plasma. The release was 2.3 -fold higher in the plasma from the patient with hereditary angioedema.

To assess the role of $\mathrm{C5a}$ in the release of elastase during coagulation, neutrophils were resuspended in C5-deficient plasma. After incubation in the presence of calcium, no difference in elastase release was noted, as compared with that of neutrophils resuspended in normal plasma (Fig. 6). Finally, $100 \mu \mathrm{l}$ of anti-C5 IgG $(17.7 \mathrm{mg} / \mathrm{ml}$ ) was preincubated with $1 \mathrm{ml}$ of normal plasma for $20 \mathrm{~min}$, at $37^{\circ} \mathrm{C}$. When neutrophils $\left(10^{7} /\right.$ $\mathrm{ml})$ were resuspended in normal plasma, or normal plasma preincubated with antibody, $3.5 \mu \mathrm{g} / \mathrm{ml}$ elastase released was observed in both mixtures.

\section{DISCUSSION}

The data presented here support the conclusions that purified plasma kallikrein not only serves as a chemotaxin (4), aggregating agent (6), and stimulator of oxidative metabolism for human neutrophils $(5,6)$, but also induces the cells to release elastase in a purified 


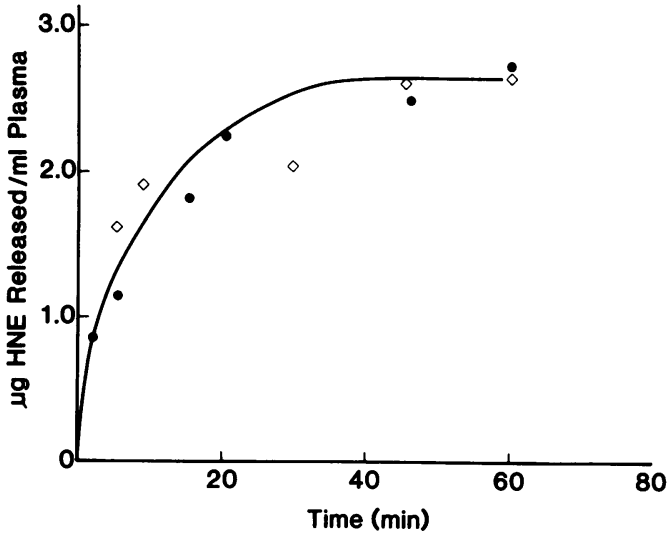

Figure 6 Influence of $\mathrm{C} 5$ on release of $\mathrm{HNE}$ in recalcified plasma. Isolated human neutrophils $\left(1 \times 10^{7}\right)$ were resuspended in either $1 \mathrm{ml}$ of $(\ominus)$ normal or $(\diamond)$ C5-deficient human plasma, containing $30 \mathrm{mM} \mathrm{CaCl}_{2}$ (final concentration). The neutrophil suspension was incubated in $12 \times 75$ $\mathrm{mm}$ polypropylene tubes at $23^{\circ} \mathrm{C}$. At selected time intervals, samples were centrifuged at $13,000 \mathrm{~g}$ for $5 \mathrm{~min}$, and HNE levels were determined in these supernatants by a competitive ELISA. This experiment represents one of two studies.

system. Moreover, during blood coagulation, the formation of kallikrein appears to be a major stimulator of elastase release from neutrophils.

In a purified system, plasma kallikrein released elastase from neutrophils, which were preincubated with cytochalasin B, an inhibitor of microfilament function. Virtually no extracellular elastase was detected in the absence of this compound. Biochemical and electron microscopic observations of neutrophils, primed with cytochalasin B, indicated that fusion of lysosomal granules with each other and with the plasma membrane allowed extracellular extrusion of enzymes normally involved in intracellular digestion within phagocytic vacuoles (17). Azurophilic granule material may be released in the absence of cytochalasin $B$ when neutrophils attach to a non-phagocytosable surface, such as opsonized zymosan (18). It is not known what component(s) in clotting plasma supports this release of elastase by neutrophils.

The release of elastase from neutrophils by kallikrein increased during the incubation period. However, most of the enzyme released was extruded extracellularly in the first $15 \mathrm{~s}$ of the reaction. This behavior is similar to the observation of Sklar et al. (19) for myeloperoxidase release after exposure to zymosan-treated serum containing $\mathrm{C5}$ a. This rapid release of elastase was not associated with leakage of lactate dehydrogenase from the neutrophils, indicating that the kallikrein released elastase by inducing granule exocytosis and not by a cytolytic effect on the neutrophils.
Kallikrein caused a rapid release of elastase from neutrophils in a purified system. This observation suggested that the release of elastase from neutrophils in clotting plasma (3) was due to the activation of prekallikrein in that plasma. We have demonstrated that the release of elastase was impaired in Factor XII and prekallikrein-deficient plasma. Since activated Factor XII, either in the form of XIIa or XII fragments, can convert prekallikrein to kallikrein, this finding suggests that kallikrein is responsible for a portion of elastase released during coagulation. This premise is further strengthened by the ability of purified prekallikrein to correct the defective elastase released when prekallikrein-deficient plasma was reconstituted. These results indicate that an early step in the coagulation cascade is responsible for neutrophil activation and subsequent elastase release, as previously suggested by the observation that coagulation of plasma, resulting from the addition of thrombin, did not induce neutrophils to release elastase (3). However, these data do not establish that kallikrein directly causes neutrophil elastase release in the plasma environment. Since Factor XII fragments can activate the classical pathway of complement $(20$, 21 ), it is possible that C5a could be responsible for at least part of the elastase release during coagulation. Furthermore, rabbit plasma kallikrein is known to produce chemotactic activity of rabbit C5 (22). To further probe these relationships, we resuspended human neutrophils in human C5-deficient plasma. The similarity of elastase release in C5-deficient and normal plasma argues against a significant role for C5a in elastase release during coagulation. Furthermore, preincubation of normal plasma with anti-C5 did not inhibit elastase release. However, this finding does not detract from the importance of C5a under other conditions.

Plow (3) reported that neutrophils were the only significant source of immunoreactive HNE in blood. Furthermore, he demonstrated that elastase was released from neutrophils during coagulation. However, he reported a markedly lower level of elastase release at $37^{\circ} \mathrm{C}$, than we did at $23^{\circ} \mathrm{C}$. This discrepancy can be explained by the fact that kallikrein, the enzyme responsible for this release, is inactivated by plasma protease inhibitors more rapidly at 37 than at $23^{\circ} \mathrm{C}$. In addition, the major plasma protease inhibitor of kallikrein, CI-inhibitor, is less active at 23 than at $37^{\circ} \mathrm{C}$, thereby allowing us to observe a greater effect of kallikrein on the neutrophils. We also observed greater release of neutrophil elastase in plasma deficient in CI-inhibitor.

The participation of kallikrein in neutrophil activation and elastase release expands our appreciation of the role of this enzyme in human disease. A number of diseases in which prekallikrein activation has been established, such as hypotensive endotoxemia (23), are 
known to be associated with neutrophil activation. Although complement activation has been implicated, kallikrein should be considered as an additional agonist. Furthermore, since neutrophil aggregation has been demonstrated in the lungs of patients with adult respiratory distress syndrome, elastase may be released in that disorder, via the mediation of plasma kallikrein.

\section{ACKNOWLEDGMENTS}

We thank Dr. Edward F. Plow for stimulating discussions, Dr. William R. Abrams for constructive criticism, and Sharyn Koch for preparing the purified prekallikrein.

This work was supported in part by National Institutes of Health grants HL-14217, HL-29823-01, and HL-24365; a grant from the Council for Tobacco Research Inc. (No. $1420)$; and a grant (3.184.0.82) of the Swiss National Science Foundation.

\section{REFERENCES}

1. Wright, D. G. 1982. The neutrophil as a secretory organ of host defense. In Advances in Host Defense Mechanisms. J. I. Gallin and A. S. Fauci, editors. Raven Press, New York. 1:75-110.

2. Janoff, A., B. Sloan, G. Weinbaum, V. Damiano, R. A. Sandhaus, J. Elias, and P. Kimbel. 1977. Experimental emphysema induced with purified human neutrophil elastase: tissue localization of the instilled protease. Am. Rev. Respir. Dis. 115:461-478.

3. Plow, E. 1982. Leukocyte elastase release during blood coagulation. A potential mechanism for activation of the alternative fibrinolytic pathway. J. Clin. Invest. 69:564573.

4. Kaplan, A. P., A. B. Kay, and K. F. Austen. 1972. A prealbumin activator of prekallikrein III. Appearance of chemotactic activity for human neutrophils by the conversion of human prekallikrein to kallikrein. J. Exp. Med. 135:81-97.

5. Goetzl, E. J., and K. F. Austen. 1974. Stimulation of human neutrophil aerobic glucose metabolism by purified chemotactic factors. J. Clin. Invest. 53:591-599.

6. Schapira, M., E. Despland, C. F. Scott, L. A. Boxer, and R. W. Colman. 1982. Purified human plasma kallikrein aggregates human blood neutrophils. J. Clin. Invest. 69:1191-1202.

7. Castillo, M. J., K. Nakajima, M. Zimmerman, and J. C. Powers. 1979. Sensitive substrates for human leukocyte and porcine pancreatic elastase. A study of the merits of various chromophoric and fluoregenic leaving groups in assays for serine proteases. Anal. Biochem. 99:53-64.

8. Shimamoto, K., J. Chao, and H. S. Margolius. 1980. The radioimmunoassay of human urinary kallikrein and comparisons with kallikrein activity measurements. $J$. Clin. Endocrinol. Metab. 51:840-848.
9. Fisher, C. A., A. H. Schmaier, V. P. Addonizio, and R. W. Colman. 1982. Assay of prekallikrein in human plasma: comparison of amidolytic, esterolytic, coagulation, and immunochemical assays. Blood. 59:963-970.

10. Baugh, R. J., and J. Travis. 1976. Human leukocyte granule elastase: rapid isolation and characterization. Biochemistry. 15:836-841.

11. Boyum, A. 1968. Isolation of mononuclear cells and granulocytes from human blood. Isolation of mononuclear cells by one centrifugation and of granulocytes by combining centrifugation and sedimentation of $1 \mathrm{~g}$. Scand. J. Clin. Lab. Invest. 21(Suppl 97):77-89.

12. Agostini, A., and G. Ideo. 1965. Separation of large numbers of lymphocytes from human blood. Experentia. 21:81-83.

13. Goldstein, I., S. Hoffstein, J. Gallin, and G. Weissman. 1973. Mechanisms of lysosomal enzyme release from human leukocytes: microtubule assembly and membrane fusion induced by a component of complement. Proc. Natl. Acad. Sci. USA. 70:2916-2920.

14. Yamada, H., V. V. Damiano, A. Tsang, D. R. Meranze, J. Glasgow, W. R. Abrams, and G. Weinbaum. 1982. Neutrophil degranulation in cadmium-chloride-induced acute lung inflammation. Am. J. Pathol. 109:145-156.

15. Kucich, U., W. R. Abrams, and H. L. James. 1980. Solid phase immunoassay of dog neutrophil elastase. Anal. Biochem. 109:403-409.

16. Reeves, W. J., and G. M. Fimognari. 1963. An improved procedure for the preparation of crystalline lactic dehydrogenase from hog heart. J. Biol. Chem. 238:38533858.

17. Zurier, R. B., S. Hoffstein, and G. Weissmann. 1973. Cytochalasin B: effect on lysosomal enzyme release from human leukocytes. Proc. Natl. Acad. Sci. USA. 70:844848.

18. Bentwood, B. J., and P. M. Henson. 1980. The sequential release of granule constituents from human neutrophils. J. Immunol. 124:855-862.

19. Sklar, L. A., V. M. McNeil, A. J. Jesaitis, R. G. Painter, and C. G. Cochrane. 1982. A continuous spectroscopic analysis of the kinetics of elastase secretion by neutrophils. J. Biol. Chem. 257:5471-5475.

20. Donaldson, V. H. 1968. Mechanisms of activation of $\mathrm{C}^{\prime} 1$ esterase in hereditary angioneurotic edema plasma in vitro. The role of Hageman factor, a clot promoting agent. J. Exp. Med. 127:411-429.

21. Ghebrehiwit, B., M. Silverberg, and A. P. Kaplan. 1981. Activation of the classical complement pathway by Hageman factor fragments. J. Exp. Med. 153:665-676.

22. Wiggins, R. C., P. C. Giclas, and P. M. Henson. 1981. Chemotactic activity generated from the fifth component of complement by plasma kallikrein of the rabbit. J. Exp. Med.153:1391-1404.

23. Mason, J. W., U. R. Kleeberg, P. Dolan, and R. W. Colman. 1970. Plasma kallikrein and Hageman Factor in gram negative bacteremia. Ann. Int. Med. 73:545-551. 